\title{
ENDOSCOPIC VERSUS HISTOPATHOLOGIC DIAGNOSIS OF PANGASTRITIS IN NEWLY DIAGNOSED DYSPEPSIA
}

\author{
By \\ Mohab M. Mansour, Sayed Abd El-Raheem*, Waleed Mousa and \\ Mostafa A. El-Hawary \\ Departments of Hepatogastroenterology \& Infectious Diseases and Pathology*, Faculty of \\ Medicine, Al-Azhar University
}

Corresponding Author: Mohab M. Mansour, E-mail: mohabmansour1001@yahoo.com

\begin{abstract}
Background: Gastritis is a very common prevalent pathological entities and endoscopists make judgements on the presence or absence of pangastritis on the basis of endoscopic appearances of the gastric mucosa.

Objective: To analyze the correlation between the endoscopic findings and the histological diagnosis of pangastritis in early dyspeptic patients.

Patients and methods: In this study was done on 180 patients complaining of newly onset dyspepsia coming to upper endoscopy unit at Al-Hussein University Hospital during from February 2019 until August 2019, after getting informed consent, detailed history was taken from patient that included dietetic, social, medical and family history of malignant diseases. Blood investigation was done, liver function test, kidney function test and complete blood count. Also abdominal ultrasonography was done in fasting patients.
\end{abstract}

Results: By endoscopy we found that $67.8 \%$ of patients have pangastritis and by histopathology found that $88.9 \%$ from patients have pangastritis. $66.7 \%$ from studied patients have pangastritis by both endoscopy and histopathology. So, sensitivity of endoscope about $81.8 \%$, and PPV about $86.9 \%$ and NPV of endoscopy in about $33.3 \%$.

Conclusion: Pangastritis was a common finding in early dyspeptic patients and endoscopy has high sensitivity in diagnosis of pangastritis and normal endoscopic appearance did not rule it out and the histopathology was still the gold standard method for diagnosis.

Keywords: Pangastritis, Endoscopy, Dyspepsia.

\section{INTRODUCTION}

Dyspepsia is a common symptom with an extensive differential diagnosis and a heterogeneous pathophysiology, It occurs in at least $20 \%$ of the population (George et al., 2019). Typical dyspeptic symptoms include postprandial fullness, early satiation, epigastric pain and epigastric burning, but other upper gastrointestinal symptoms such as nausea, belching or abdominal bloating often occur (Tack and
Talley, 2013). Functional dyspepsia accounts for up to $60 \%$ of cases and Gastroduodenal ulcer disease is found in approximately $15 \%-25 \%$ of patients with dyspepsia (Brunj, 2010).

The term gastritis was first used in 1728 by Stahl. which is a very common condition, and its prevalence increases with age. After the age of 60 , the prevalence of gastritis varies from $50 \%$ to $100 \%$ and appears to be higher in low 
socioeconomic populations. Mostly due to Helicobacter pylori (Luiz et al., 2018). It characterized by chronic inflammatory infiltrate, neutrophilic infiltration, presence of lymphoid follicles and aggregates and surface epithelial damage (Jayanthi et al., 2017). There is still controversy about the term pangastritis with dyspepsia mainly due to the lack of correlation between the clinical, endoscopic and histological manifestations.

The present study aimed to compare between endoscopic finding and histologic diagnosis of pangastritis in newly diagnosed dyspepsia.

\section{PATIENTS AND METHODS}

To accomplish this study, 180 patients complaining of newly onset dyspepsia coming to upper endoscopy unit at AlHussein University Hospital from February 2019 until August 2019. After getting informed consent, detailed history (included dietetic, social, medical and family history of malignant diseases) was taken from all patients followed by medical examination. Investigations included liver function, kidney function tests, complete blood count and abdominal ultrasonography.

Patients known to have chronic liver disease, chronic kidney diseases. Cancer patients or drug abuse were excluded from our study. Endoscopic examination: included upper EGD was performed using GIF-Q260 (Olympus Co., Tokyo, Japan) after local pharyngeal anesthesia by lidocaine spray and sedation. Endoscopic examination was done and multiple biopsies were taken from fundus, body and antrum. Each specimen was put in a separate tube containing diluted formalin with special code number 1 for antral, code number 2 for body and number 3 for fundal biopsy for each patient and sent to histological examination.

\section{Statistical analysis:}

Data were verified, coded by the researcher and analyzed using IBM-SPSS Statistics for windows, version 23.0 (Copyright IBM Corp., Armonk, N.Y., USA. 2015). Descriptive statistics: Means, standard deviations, medians, ranges and percentages were calculated. Test of significances: chi-square test was used to compare the difference in distribution of frequencies among different groups. For continuous variables; independent t-test analysis was carried out to compare the means of dichotomous data. There was no specific calculation of the sample size. Positive, Negative, Sensitivity, Specificity, PPV, NPV and Accuracy were included. A significant $\mathrm{p}$-value was considered when it was equal or less than 0.05 . 


\section{RESULTS}

As regard age, the mean age of all studied patients was $41.5 \pm 14.5$ years with minimum age of 18 years and maximum age of 67 years. As regard sex, there were 88 males $(48.9 \%)$ and 92 females $(51.1 \%)$ in the studied patients. As regard Scio-economic status, there were 94 patients $(52.2 \%)$ with low status,
80 patients $(44.4 \%)$ with moderate status and 6 patients $(3.3 \%)$ with high status in the studied patients. As regard risk factors, there were 26 smoker patients (14.4\%), 106 Patients (58.9\%) taking NSAIDs and 22 patients $(12.2 \%)$ taking steroids in the studied patients (Table 1).

Table (1): Description of demographic data and risk factors of all studied patients

\begin{tabular}{|c|c|c|c|c|}
\hline \multicolumn{3}{|c|}{ Demographic data and Risk factors } & \multicolumn{2}{|c|}{$(\mathrm{N}=180)$} \\
\hline \multirow{7}{*}{ 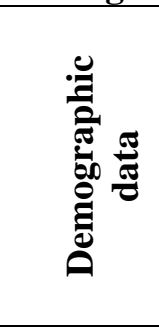 } & \multirow{2}{*}{ Age (years) } & Mean \pm SD & \multicolumn{2}{|c|}{$41.5 \pm 14.5$} \\
\hline & & Min - Max & \multicolumn{2}{|c|}{$18-67$} \\
\hline & \multirow{2}{*}{ Sex } & Male & 88 & $48.9 \%$ \\
\hline & & Female & 92 & $51.1 \%$ \\
\hline & \multirow{3}{*}{ Scio-economic status } & Low & 94 & $52.2 \%$ \\
\hline & & Moderate & 80 & $44.4 \%$ \\
\hline & & High & 6 & $3.3 \%$ \\
\hline \multirow{6}{*}{$\frac{\pi}{0}$} & \multirow{2}{*}{ Smoking } & Non-smoker & 154 & $85.6 \%$ \\
\hline & & Smoker & 26 & $14.4 \%$ \\
\hline & \multirow{2}{*}{ NSAIDs } & No & 74 & $41.1 \%$ \\
\hline & & Yes & 106 & $58.9 \%$ \\
\hline & \multirow{2}{*}{ Steroid } & No & 158 & $87.8 \%$ \\
\hline & & Yes & 22 & $12.2 \%$ \\
\hline
\end{tabular}

The mean $\mathrm{Hb}$ of all studied patients was $12.2 \pm 1.5 \mathrm{~g} / \mathrm{dl}$ with minnimum $\mathrm{Hb}$ of $8 \mathrm{~g} / \mathrm{dl}$ and maximum $\mathrm{Hb}$ of $15 \mathrm{~g} / \mathrm{dl}$. As regard TLC, the mean TLC of all studied patients was $7.9 \pm 2.1(\mathrm{x} 103 / \mathrm{cmm})$ with minimum TLC of 5 (x 103/cmm) and maximum TLC of 14 (x 103/cmm). The mean PLT of all studied patients was $299.4 \pm 72.8$ (x 103/cmm) with minimum PLT of 145 (x 103/cmm) and maximum PLT of 470 (x 103/cmm). The mean Creat of all studied patients was $0.8 \pm 0.2$ $(\mathrm{mg} / \mathrm{dl})$ with minimum Creat of 0.3 $(\mathrm{mg} / \mathrm{dl})$ and maximum Creat of 1.3 $(\mathrm{mg} / \mathrm{dl})$. The mean ALT of all studied patients was $19.9 \pm 4$ (U/L) with minimum ALT of 2 (U/L) and maximum ALT of 34 (U/L). The mean AST of all studied patients was $28.1 \pm 7.2(\mathrm{U} / \mathrm{L})$ with minimum ALT of 12 (U/L) and maximum ALT of 43 (U/L) (Table 2).

Table (2): Description of laboratory data in all studied patients

\begin{tabular}{|l|c|c|c|c|}
\hline Description & Mean & Std. Deviation & Minimum & Maximum \\
\hline Hb (g/dl) & 12.2 & 1.5 & 8 & 15 \\
\hline TLC (x 10 $/$ /cmm) & 7.9 & 2.1 & 5 & 14 \\
\hline PLT (x 10 $/ \mathbf{c m m})$ & 299.4 & 72.8 & 145 & 470 \\
\hline Creat (mg/dl) & 0.8 & 0.2 & 0.3 & 1.3 \\
\hline ALT (U/L) & 19.9 & 4.0 & 2 & 34 \\
\hline AST (U/L) & 28.1 & 7.2 & 12 & 43 \\
\hline
\end{tabular}


There was a statistical significant difference $(\mathrm{p}$-value $<0.001)$ between endoscopic and histo-pathological results (Table 3).

Table (3): Comparison between endoscopic and Histo-pathological results

\begin{tabular}{|c|c|c|c|c|c|}
\hline $\begin{array}{ll}\text { Results } & \text { Methods }\end{array}$ & \multicolumn{2}{|c|}{$\begin{array}{c}\text { Endo } \\
(\mathbf{N}=\mathbf{1 8 0})\end{array}$} & \multicolumn{2}{|c|}{$\begin{array}{c}\text { Histo } \\
(\mathrm{N}=\mathbf{1 8 0})\end{array}$} & P-value \\
\hline Normal & 42 & $23.3 \%$ & 16 & $8.9 \%$ & \multirow{3}{*}{$<0.001$} \\
\hline Antral gastritis & 16 & $8.9 \%$ & 4 & $2.2 \%$ & \\
\hline Pangastritis & 122 & $67.8 \%$ & 160 & $88.9 \%$ & \\
\hline
\end{tabular}

$\mathrm{X} 2$ : Chi-square test.

The description of endoscopic results in all studied patients. Showed that 42 patients $(23.3 \%)$ normal, 16 patients
(8.9\%) with antral gastritis, and 122 patients $(67.8 \%)$ with pangastritis (Table 4).

Table (4): Describe total result of endoscopy and histopathology

\begin{tabular}{|c|c|c|c|}
\hline \multicolumn{4}{|c|}{ Endoscopy result } \\
\hline Normal & Pangastritis & Antral gastritis & Total cases \\
\hline 42 & 122 & 16 & 180 \\
\hline \multicolumn{4}{|c|}{ Histopathology result } \\
\hline Normal & Pangastritis & Antral gastritis & Total cases \\
\hline 16 & 160 & 4 & 180 \\
\hline
\end{tabular}

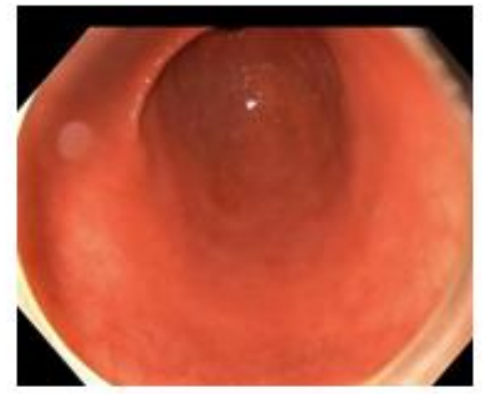

Figure (1): Diffuse hypremia in antrum of Figure (2): Diffuse hypremia in the fundus the stomach indicated antral gastritis.

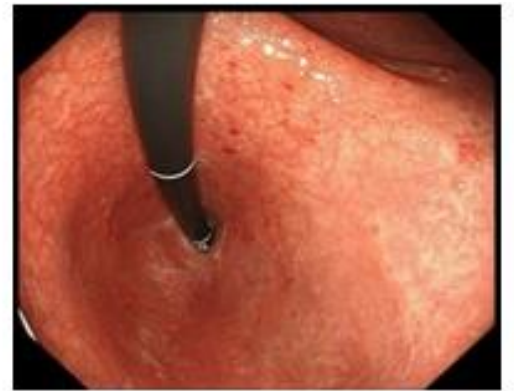

of the stomach indicated fundal gastritis. 


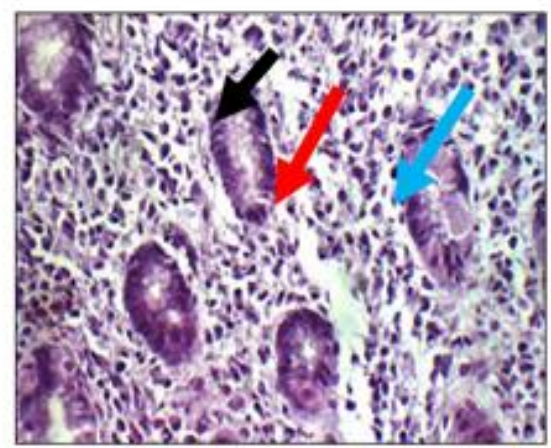

Figure (3): Chronic gastritis showed mild activity, widely-spaced gastric glands (red arrow), marked inflammatory infiltrate composed of plasma cells (black arrow), lymphocytes (blue arrow) (H\&E X 400).

The Diagnostic performance of endoscope in relation to Histopathology results showed that. Total studied patients were 180 patients. There were 120 patients $(66.7 \%)$ true positive, 14 patients $(7.8 \%)$ true negative, 18 patient $(10 \%)$

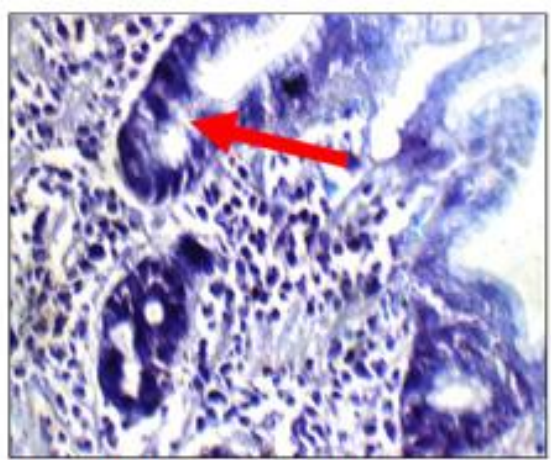

Figure (4): Chronic gastritis, H. pylori associated: gastric wall showing $H$. pylori attached to mucosal surface (red arrow)

(Geimsa stain X 400).

false positive and 28 patients (15.6\%) false negative. Thus endoscope had the sensitivity of $81.8 \%$, specificity of $43.8 \%$, PPV of $86.9 \%$, NPV of $33.3 \%$ and accuracy of $74.4 \%$ in diagnosis of pangastritis (Table 5).

Table (5): Accuracy of endoscope in relation to histopathology in diagnosis of pangastritis

\begin{tabular}{|c|c|c|c|c|c|c|c|}
\hline \multicolumn{2}{|c|}{ True positive } & \multicolumn{2}{|c|}{ True negative } & \multicolumn{2}{|c|}{ False positive } & \multicolumn{2}{|c|}{ False negative } \\
\hline 120 & $66.7 \%$ & 14 & $7.8 \%$ & 18 & $10 \%$ & 28 & $15.6 \%$ \\
\hline \multicolumn{2}{|c|}{ Sensitivity } & \multicolumn{2}{|c|}{ Specificity } & \multicolumn{2}{|c|}{ PPV } & NPV & Accuracy \\
\hline \multicolumn{2}{|c|}{$81.8 \%$} & \multicolumn{2}{|c|}{$43.8 \%$} & \multicolumn{2}{|c|}{$86.9 \%$} & $33.3 \%$ & $74.4 \%$ \\
\hline
\end{tabular}

\section{DISCUSSION}

Dyspepsia is a common symptom with an extensive differential diagnosis and a heterogeneous pathophysiology. It occurs in at least $20 \%$ of the population, but most affected people do not seek medical care (George et al., 2019). Functional dyspepsia, accounts for up to $60 \%$ of cases and Gastroduodenal ulcer disease is found in approximately $15 \%-25 \%$ of patients with dyspepsia (Brunj, 2010).

In our study, we made a comparative study between the endoscopic and histopayhologic in diagnosis of pangastritis in those patients 180 patients enrolled in our study, as regard sex, there were males $(48.9 \%)$ and females $(51.1 \%)$ in the studied patients. As regard Scioeconomic status, there were $(52.2 \%)$ from patients with low status, $(44.4 \%)$ patients with moderate status and $(3.3 \%)$ from patients with high status in the studied patients. As regard risk factors, there were 26 smoker patients (14.4\%), 106 Patients (58.9\%) taking NSAIDs and 22 patients $(12.2 \%)$ taking steroids in the studied patients.

As regarding risk factors of pangastritis, we found that $58 \%$ from patients were diagnosed as pangastritis have history of NSAIDS intake. Only 
$15 \%$ from pangastritis patients have positive history of smoking. This due to the high percentage of female patients in our study. H.pylori was positive in $80 \%$ of patients have pangastitis.

We found that dyspepsia was more common in female with no significance statistical difference as regard sex. This agreed with meta-analysis by Ford et al. (2015) who assessed the prevalence of dyspepsia according to gender in 55 studies and found a slightly higher prevalence of dyspepsia in women compared with men. Johnsen et al. (2010), found a significantly higher rate of FD in men compared with women .

According to symptoms of the patients we found that $41.1 \%$ from studied patients complaining of epigastric pain, then early satiation in $38.9 \%$, post prandial fullness in $35.6 \%$ followed by epigastric burning in $32.8 \%$ of all studied patients. This agreed with Seid et al. (2018) who stated that $42 \%$ from studied patient present with epigastric pain

Results were in line with study as epigastric pain or burning $(58.3 \%)$ being dominant complaint of dyspeptic patients (Seyedmirzaei et al., 2014).

Regarding gastritis we found that gastritis were common in female (52\%) This agreed with de Miranda et al. (2019) that female was more than male in gastritis but with no significance difference.

According to the risk factor of dyspepsia, we find that $85.6 \%$ from cases has negative history of smoking. This was against Jaber et al. (2016) that there is a strong association between dyspepsia and smoking.
In another study by Khalifa et al. (2014), no statistically significant difference between smokers, non-smokers and ex-smoker in the positivity rate of $\mathrm{H}$. pylori in dyspeptic patients.

Regarding to gastritis and smoking we found that from in patients have gastritis by histopathology, only $15 \%$ from patient have positive history of smoking this agree with study by Namiot et al. (2011) who stated that In the $\mathrm{H}$. pylori infected population, H. pylori density, neutrophils, and mononuclear cells infiltration were lower in smokers than non-smokers, In the non-infected population, no significant differences in neutrophils and mononuclear cells infiltration between smokers and non-smokers were found.

In the present study, only $14.4 \%$ have positive history of smoking this may duo to the high percentage of female included in study.

Another study with same result stated that Smoking seems to decrease inflammation in the gastric body and to delay atrophic changes in the gastric body. Subsequently, the prevalence of duodenal ulcers increased (Koivisto et al., 2012).

Nakamura et al. (2010) concluded that smoking increased risk of severe atrophic gastritis and intestinal metaplasia.

Regarding to NSAID and dyspepsia $58.8 \%$ has positive history and $41.1 \%$ has negative history which means NSAID increase risk of dyspepsia. A study by Straus et al. (2010) show that based solely on epigastric pain-related symptoms, NSAIDs increased the risk of dyspepsia by $36 \%$.

Meta-analysis concluded that high dosages of any NSAID along with any 
dosage of indomethacin, meclofenamate, or piroxicam increase the risk of dyspepsia by about 3-fold. Other NSAIDs at lower dosages were not associated with an increased risk of dyspepsia (Joshua at al., 2010).

Regarding to relation between gastritis and NSAIDs we found that from $85 \%$ of patients have history of NSAIDs intake. So, NSAID increase risk of gastritis this agreed with Hakki (2017) concluded that these medication increase risk of gastritis and hazardous to GIT tract and proved that judicious use of these medication is required to prevent its untoward side effects.

In our study by endoscopy, we found that $67.8 \%$ of patients have pangastritis, $8.9 \%$ have antral gastritis, and $23.3 \%$ have normal gastric mucosa, Biopsies taken from antrum, body and fundus examined histopathologically found that $88.9 \%$ from patients have pangastritis $2.2 \%$ have antral gastritis, and $8.9 \%$ have normal mucosa. $66.7 \%$ from studied patients showed pangastritis by both endoscopy and histopathology. Sensitivity of endoscope in diagnosis of pangastritis was about $81.8 \%$. We found that $10 \%$ from patients diagnosed as pangastritis by endoscopy their histopathology examination showed that their mucosa were normal, and no pangastritis in it. So, PPV of endoscopy in diagnosis of pangastritis about $86.9 \% .23 .3 \%$ from all studied patients were diagnosed by endoscopy as normal mucosa, but according to histopathology only $8.9 \%$ from all studied patients have normal mucosa. So NPV of endoscopy in pangastritis was about $33.3 \%$. So, we can conclude that normal endoscopic appearance was a poor predictor of the absence of pangastritis, this agree with study by Jemilohun et al. (2010) who concluded a good association between the presence of endoscopic gastritis and histological gastritis, and a very poor association between normal endoscopic mucosa and normal histology. Another study of patients complaining of dyspepsia, most were diagnosed as gastritis both endoscopically and histologically giving a concordance of 88.4\% (Akande et al., 2015).

Another study by Taweesak et al. (2015) showed that present study of the correlation between gastric mucosal morphologic pattern and histological gastritis severity (using the updated Sydney classification) showed a good correlation between the gastric mucosal morphologic pattern and the severity of gastritis. Another study by Fabio et al. (2018) showed no significant agreement between the endoscopic findings and the histological diagnosis of antral gastritis.

\section{CONCLUSION}

Pan-gastritis is a common finding in early dyspeptic patients and endoscopy has high sensitivity in diagnosis of pangastritis and normal endoscopic appearance did not rule it out, and the histopathology was still the gold standard method.

Ethical aspect: The current protocol was approved by the Committee of Hepatogastro-enterology and infectious disease department and by the Committee of Faculty of Medicine Al-Azhar University. 
Patients consent: All patients that included in this study signed approved consents.

Financial support and sponsorship: Nil.

Conflicts of interest: None declared.

\section{REFERENCES}

\section{Akande O, Ebenezer A and Olusoji} A. (2015): Corelation between the Endoscopic and Histologic Diagnosis of Gastritis. International Journal of Internal Medicine, 4(1): 9-13.

2. Brunj R. (2010): Functional dyspepsia. Therap Adv Gastroenterol., 3(3): 145-164.

3. de Miranda AA, Caldato C, Said M and Levy C (2019): Gender, age, endoscopic findings, urease and helicobacter pylori: all uncorrelated within a sample of a high gastric cancer prevalence population in amazon 16784219Arq. Gastroenterol., 56: 3 -12.

4. Fábio N, Geterson B, Edno S, Fernando $M$ and Klaus R. (2018): Comparison between the endoscopic findings and the histological diagnosis of antral gastrites Arq. Gastroenterol., 55: 3-10.

5. Ford AC, Marwaha A, Sood $R$ and Moayyedi P. (2015): Global prevalence of, and risk factors for, uninvestigated dyspepsia: a metaanalysis. Gut., 64(7): 1049-1057.

6. George $F$, Brian E, Nicholas $J$ and Shilpa G. (2019): Approach to the adult with dyspepsia. Am J Gastroenterol., 112:212-219.

7. Hakki SA. (2017): NSAID Induced Gastritis and its Prevention through
Education. Sch J App Med Sci., 5(7):2496-2499

8. Jaber N, Oudah M, Kowatli A and Jibril J. (2016): Dietary and Lifestyle Factors Associated with Dyspepsia among Pre-clinical Medical Students in Ajman, United Arab Emirates. Central Asian Journal of Global Health, 5(1): 192-202.

9. Jayanthi C, Lavanya M, Rajesh $\mathbf{K}$ and Arun K. (2017): Histopathological analysis of chronic gastritis and correlation of pathological features with helicobacter pylori. Indian Journal of Pathology and Oncology, 4(4):495500.

10. Jemilohun AC, Otegbayo JA, Samuel $O O$ and Akere A. (2010): Prevalence of Helicobacter pylori among Nigerian patients with dyspepsia in Ibadan. Pan Afr Med J., 6:18-24.

11. Johnsen R, Straume $B$ and Forde OH. (2010): Peptic ulcer and nonulcer dyspepsia a disease and a disorder. Scand. J. Prim. Health Care, 6(4): 239-243.

12. Joshua J, Catherine $H$ and Walter L. (2010): Meta-Analysis Of Dyspepsia And Nonsteroidal Anti Inflammatory Drugs Arthritis \& Rheumatism. Arthritis Care \& Research, 49: 4-9.

13. Khalifa MAA, Khodiarc $S$ and AbdAlmaksoudd A. (2014): Cigarette smoking status and Helicobacter pylori infection in nonulcer dyspepsia patients. Egyptian Journal of Chest Diseases and Tuberculosis, 63(3): 695-699. 
14. Koivisto TT, Voutilainen ME and Färkkilä MA. (2012): Effect of smoking on gastric histology in helicobacter pylori-positive gastritis. Scand J Gastroenterol., 43(10):117783.

15. Luiz C, Fábio N, Geterson B, Edno $S$, Fernando $M$ and Klaus $R$. (2018): Comparison Between The Endoscopic Findings And The Histological Diagnosis of Antral Gastritis. Arq Gastroenterol., 55:1623.

16. Nakamura $M$, Tomoari $K$ and Mitsuhiro M. (2010): Cigarette smoking promotes atrophic gastritis in helicobacter pylori-positive subjects. Digestive Diseases and Sciences, 47: 675-681.

17. Namiot A, Kemona $A$ and Namiot Z. (2011): Smoking Habit and Gastritis Histology. Adv Med Sci., 52:191-5.

18. Seid A, Zemenu $T$ and Wondmagegn D. (2018): Uninvestigated dyspepsia and associated factors of patients with gastrointestinal disorders in Dessie Referral Hospital, Northeast Ethiopia. BMC Gastroenterol., 18: 13-19.

19. Seyedmirzaei SM, Haghdoost AA, Afshari $M$ and Dehghani A. (2014): Prevalence of dyspepsia and its associated factors among the adult population in southeast of Iran in 2010. Iran Red Crescent Med J., 16(11):14757-765.

20. Tack $J$ and Talley N (2013): Functional dyspepsia - Symptoms, definitions and validity of the Rome III criteria. Nature reviews. Gastroenterology \& Hepatology, 10: 134-41.

21. Taweesak T, Soraya K, Natthawut K, Chavaboon D, Ryan $\mathrm{AL}$ and Likit M. (2015): Correlation between Gastric Mucosal Morphologic Patterns and Histopathological Severity of Helicobacter pylori Associated Gastritis Using Conventional Narrow Band Imaging Gastroscopy, Hindawi Publishing Corporation. Bio Med Research International, 80: 5-7. 
در اسة مقارنة بين منظار المعدة و التشخيص الخلوى في

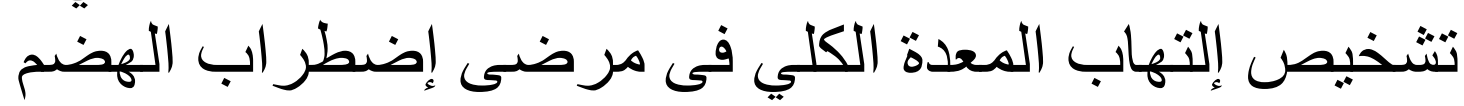

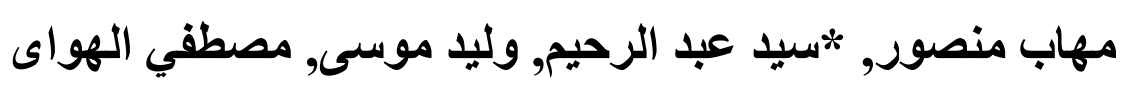

قسمي الكبل والجهاز الهضمى والامراض المعلة, الباثولوجى*, كلية الطب، جامعة الازهر

E-mail: mohabmansour1001@yahoo.com

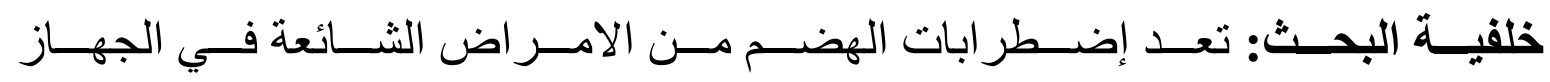

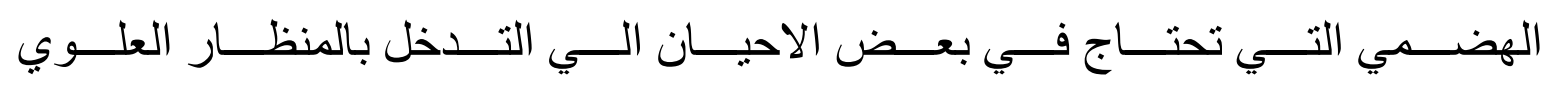

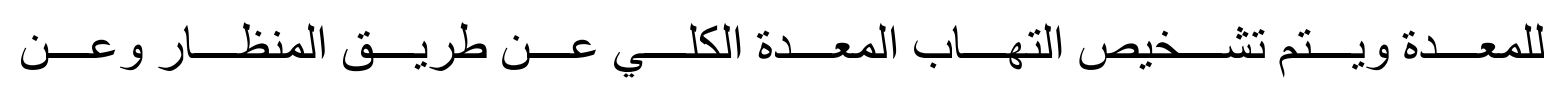

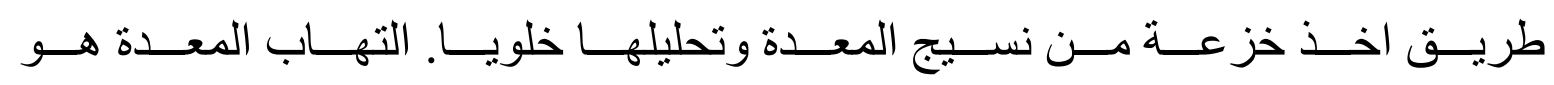

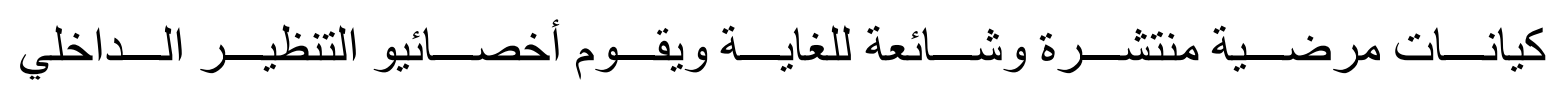

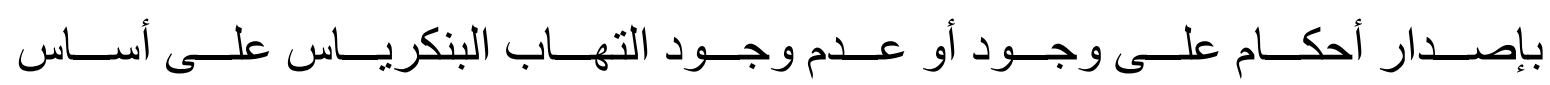
المظاهر التنظيرية للغثاء المخاطي في المعدة.

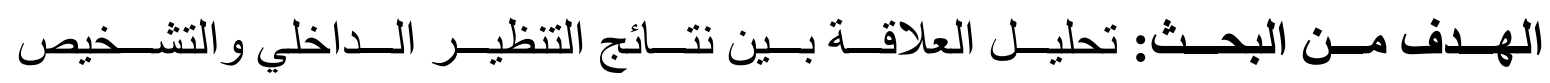
النسيجي لالتهاب البنغستريتيس في مرضى عسر الهضم المبكر.

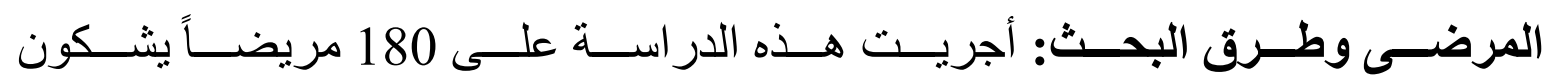

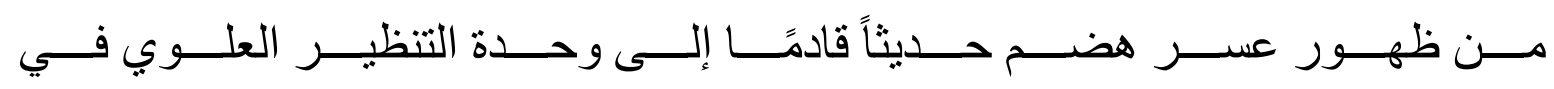

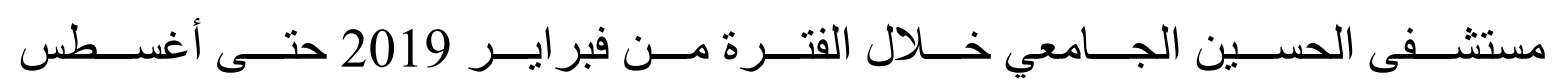

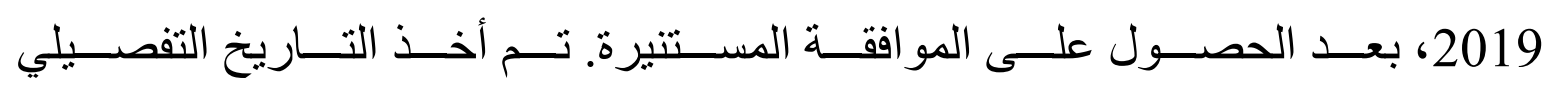

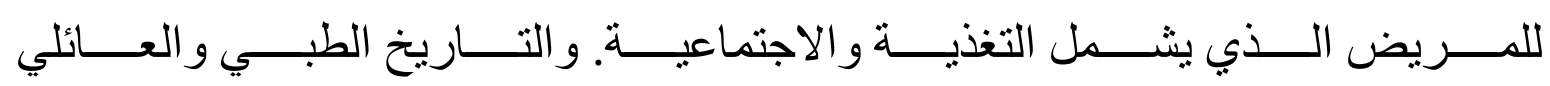

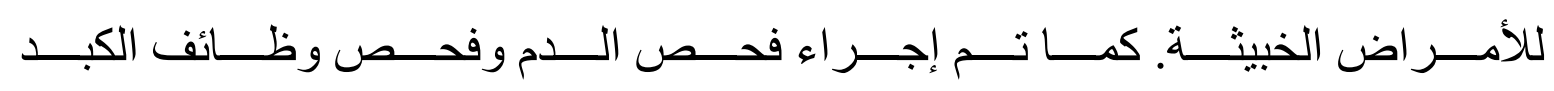

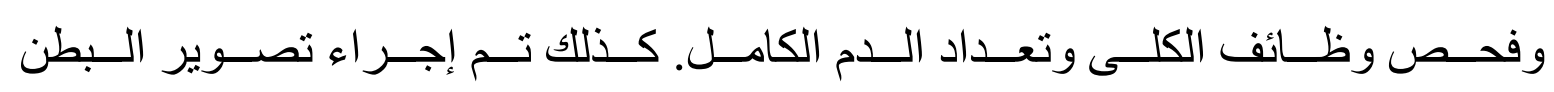
بالموجات فوق الصوتية للمرضى الصائمين. 


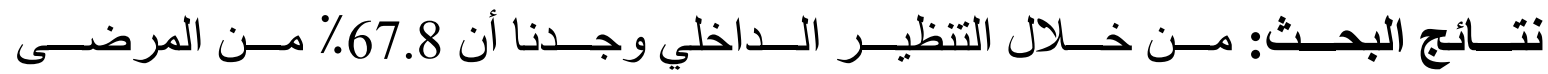

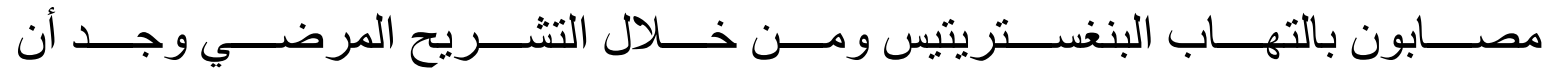

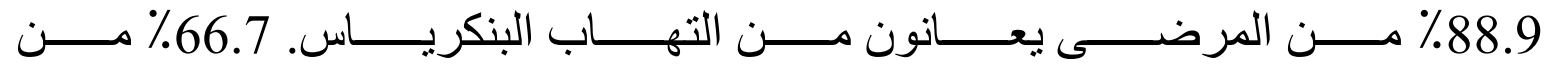

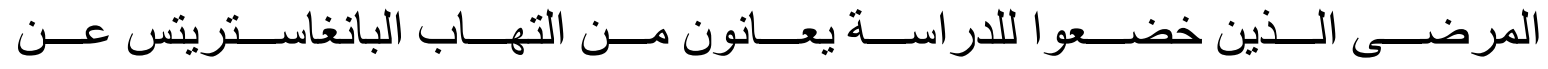

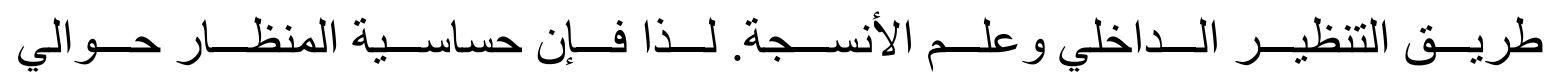

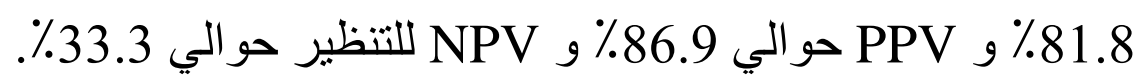

الاســتنتاج: كــان التهـاب المعـدة الكلــى مــن الاكتشــافات الثــائعة فــي مرضــى

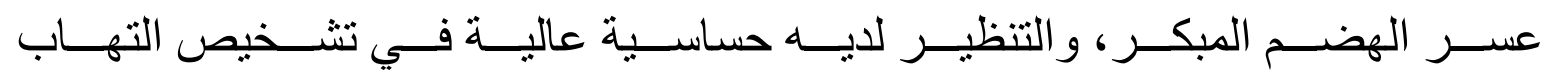

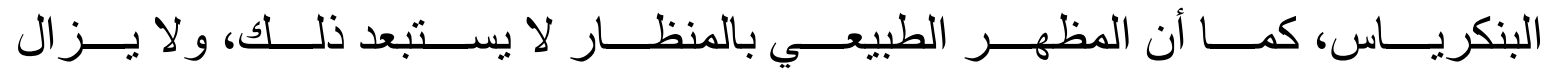
التشريح المرضي هو الأسلوب القياسي الذهبي للنتخيص. الكلمات الدالة: التهاب المعدة والأمعاء، التنظير، عسر الهضم. 